\title{
Multiple Smooth Muscle Hypertrophies in a Newborn Infant
}

\author{
J. COCKER^ and R. M. THOMSON \\ From the Department of Pathology, St. Mary's Hospital, Manchester, and the Department of Obstetrics and Gynaecology, \\ University of Manchester
}

Transient neonatal myasthenia gravis is a rare disease; it affects an estimated $15 \%$ of all babies born to myasthenic mothers. Since the condition was first described by Strickroot, Schaeffer, and Bergo (1942), reports have appeared in English of 42 patients, 4 of whom died in the neonatal period.

Intestinal smooth muscle hypertrophy is extremely rare in infancy and childhood; to our knowledge only 2 cases have been recorded (Pritchard and Hillier, 1920; Guthrie, 1945). We present a further case of intestinal smooth muscle hypertrophy in an infant dying soon after delivery from a myasthenic mother who had been treated with large doses of neostigmine throughout pregnancy. A possible relationship between the two is considered.

\section{Case Report}

A woman of 37 who had been myasthenic since the age of 20 had a thymectomy when she was 22 . Her first two pregnancies were terminated because of deterioration in her disease. The first and second trimesters of her third pregnancy were uneventful. She was admitted to St. Mary's Hospital at 36 weeks with ruptured membranes and draining slightly meconium-stained liquor, but not in labour. Her treatment was $45 \mathrm{mg}$. neostigmine hourly throughout pregnancy, pyridostigmine $60 \mathrm{mg}$. every 3-4 hours as required after admission, atropine $0.6 \mathrm{mg}$. orally with the first daily dose of neostigmine and once during the evening. A myasthenic crisis occurred, during which she stopped breathing, became cyanotic, and comatose. A period of anoxia ensued before a tracheostomy was performed, because of difficulty in maintaining an airway. She never regained consciousness and died 35 hours later. Necropsy showed multiple recent infarcts of the brain and thrombi in both arteries and veins supplying the infarcted areas.

A limp cyanosed infant with a heart rate of 60 beats a minute was delivered by caesarean section 4 hours after the initial episode. Mucus and liquor were sucked out of the mouth and oxygen was given by face mask. Only 3 gasps occurred in the first 5 minutes, but despite an improvement in colour the heart rate remained the same; so the infant was intubated and oxygen was given by

\footnotetext{
Received October 12, 1965.

* Present address: Department of Pathology, Derbyshire Royal Infirmary, Derby.
}

intermittent positive pressure. No further spontaneous respiration occurred. Neostigmine $0.1 \mathrm{mg}$. and lobeline gr. 1/40 were given intravenously at 9 minutes with no response, the heart stopped at 15 minutes.

Necropsy. The infant, weight $3.02 \mathrm{~kg}$., crown heel length $49 \mathrm{~cm}$., had no external evidence of disease. The cerebral white matter and meningeal vessels were moderately congested. The heart $(\mathbf{4 2} \mathrm{g}$.) was enlarged to twice its normal weight because of gross hypertrophy and dilatation of the right ventricle and moderate hypertrophy of the left ventricle. The valves, septa, and great vessels were normal. The lungs were small (weight $27 \mathrm{~g}$., expected weight 55 g.) and very congested. The left lung had interstitial emphysema on its cardiac surface.

The peritoneal cavity contained amber fluid, and there was considerable retroperitoneal oedema. The lower two-thirds of the oesophagus and the pylorus were much hypertrophied, and the stomach was slightly hypertrophied. The rectum and colon were empty, and their walls were moderately hypertrophied. Both kidneys were moderately enlarged and contained numerous small cortical cysts. The pelves were dilated, and the ureters dilated and tortuous. The empty bladder had a thick wall whose mucosa was thrown into folds. The urethra was normal.

The placenta, weight 740 g., was bulky and contained a large white infarct. There was no other microscopic lesion.

Microscopy. The lungs were abnormal, showing alveolar collapse with very dilated capillaries bulging into the alveoli, little interalveolar connective tissue, and interstitial emphysema. There was no inhaled amniotic debris, and the pulmonary vessels were normal.

The oesophagus, pylorus, and large intestine all showed considerable hypertrophy of the circular muscle, and to a lesser extent of the longitudinal muscle and muscularis mucosae (Fig. 1-5). The circular muscle of the stomach was slightly hypertrophied. The intestinal mucosa was normal. The myenteric plexi were prominent, especially in the colon. The hypertrophied cardiac muscle contained little glycogen (Best's Carmine technique). The bladder showed hypertrophy of the muscle and submucosal oedema; the transitional epithelium was normal. The kidneys contained areas of normal glomeruli and tubules, surrounded by a slight 


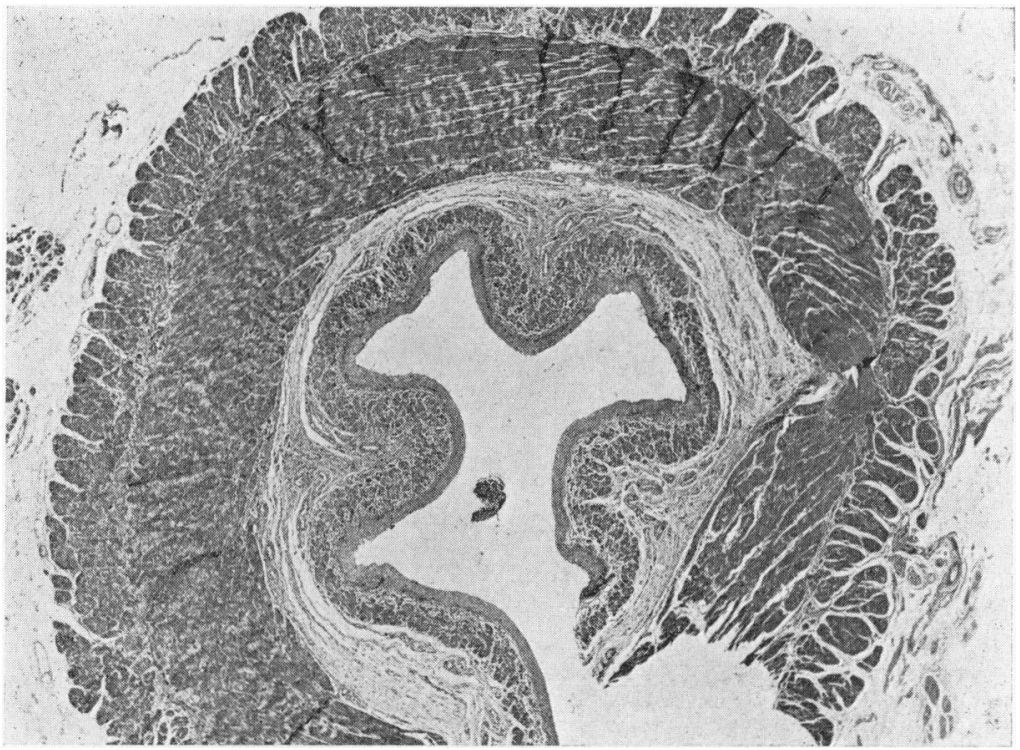

FIG. 1.-Lower oesophagus showing considerable circular muscle hypertrophy and slight longitudinal and muscularis mucosae hypertrophy. (H. and E. $\times$ 17.) Compare normal, Fig. 2.

excess of fibrous tissue and numerous cortical cysts of tubular origin. The pectoral and sterno-mastoid muscles appeared normal.

\section{Discussion}

The reported deaths in infants with transient neonatal myasthenia gravis have occurred after several days (Table) and, when performed, the necropsy findings were non-specific. Our case differs because death occurred early, the result of intrauterine anoxia, and the presence of transient neonatal myasthenia was not confirmed. In addi-

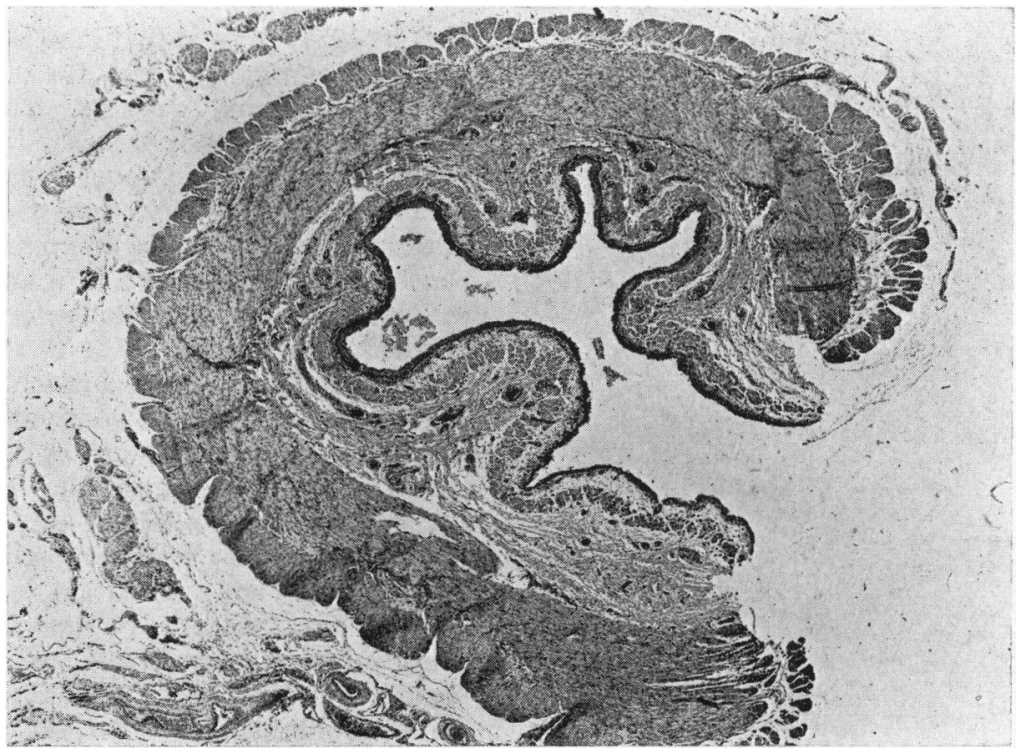

FIG. 2.-A normal oesophagus. (H. and $E . \quad \times 17$.) 


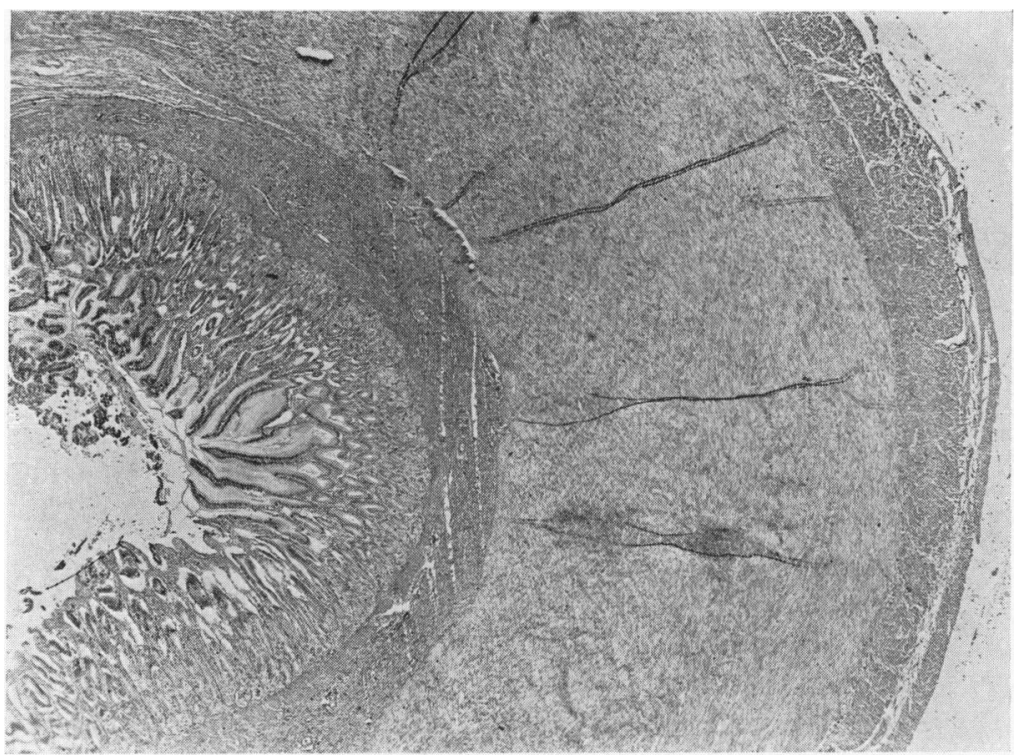

FIG. 3.-Pylorus, showing marked hypertrophy of the circular muscle. The muscularis mucosae and longitudinal muscle is slightly hypertrophied. (H. and E. $\times 17$.) Compare normal, Fig. 4.

tion, smooth muscle hypertrophy predominantly involving the inner circular muscle of the lower oesophagus, pylorus, colon, and rectum was a

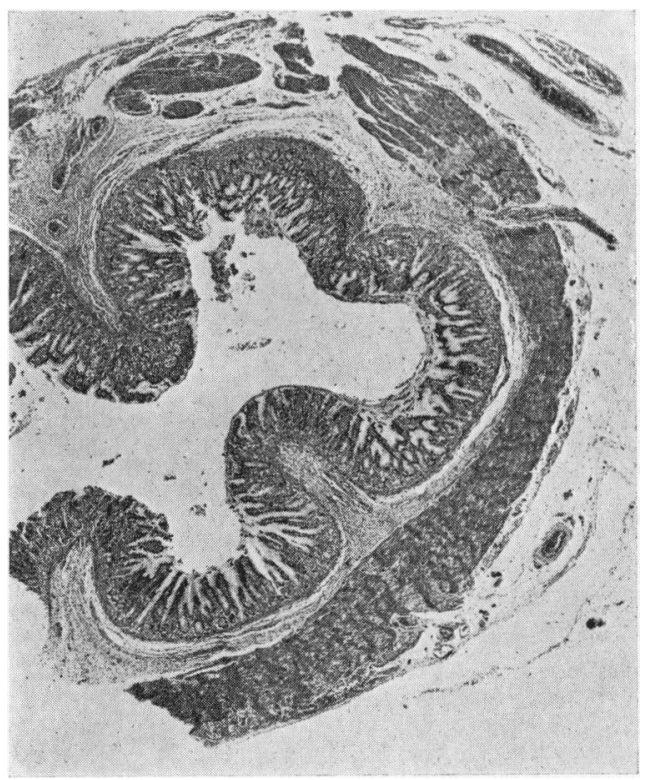

Fig. 4.-A normal pylorus. (H. and E. $\times 17$. prominent feature. Cardiac and bladder hypertrophy, polycystic kidneys, and abnormal lungs were not seen in the previously described cases of intestinal muscular hypertrophy. The pulmonary aspects of this case are discussed elsewhere (unpublished observations).

Sloper (1954) showed that muscular hypertrophy of the lower oesophagus was due to diffuse spasm. Although he found variable degrees of lower oesophageal hypertrophy associated with congenital pyloric stenosis, he could not establish a relationship with myasthenia gravis where neostigmine treatment might cause lower oesophageal spasm. Rintoul and Kirkman (1961) demonstrated the absence of Dogiel type I neurones in congenital pyloric stenosis, but were unable to decide which of the two current theories was correct: degeneration subsequent to excessive parasympathetic stimulation, or delayed development. Colonic hypertrophy, as in Hirschsprung's disease, is invariably combined with dilatation and is secondary to degeneration of the myenteric plexi at the rectosigmoid junction.

Hypertrophy and distension of the bladder usually follows urinary outflow obstruction by urethral valves or stenosis. A few cases of bladder hypertrophy occur without distension or demonstrable urethral obstruction (Potter, 1961). In addition, the tubular cysts of primary polycystic kidneys are 


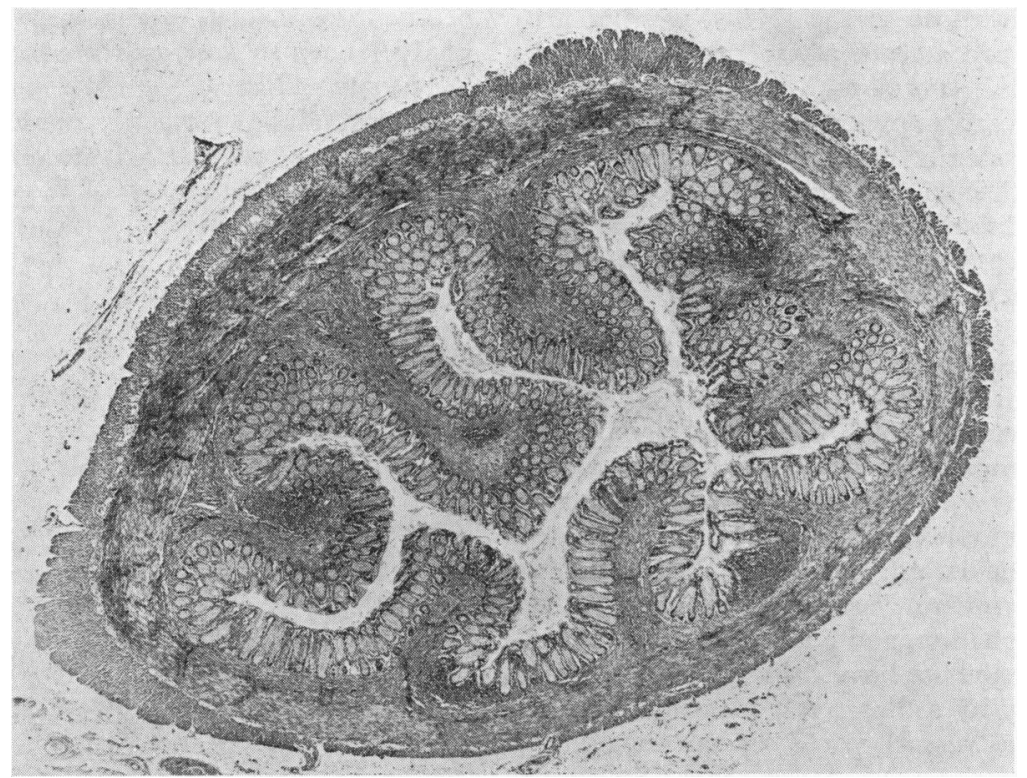

FIG. 5.-Rectum, showing moderate circular muscle hypertrophy. (H. and E. $\quad \times 18$.

indistinguishable microscopically from those caused by back pressure from urinary outflow obstruction in utero (Potter, 1961). The presence of moderate hydronephrosis and hydroureter is consistent with an obstructive origin in this case. As there was no urethral lesion the mechanism is obscure; tonic or intermittent spasm of the bladder wall causing obstruction to urinary flow through the ureters by compression is a possibility.

Since death occurred soon after birth, these abnormalities must have had an intrauterine origin. Helmke (1939) has suggested that vagal overactivity causes cardiac and upper intestinal hypertrophy. All the hypertrophies in this case are compatible with continued parasympathetic stimulation. Neostigmine, by potentiating the muscarine action of acetylcholine on smooth muscle, mimics parasympathetic stimulation. In moderate doses it increases the tone and stimulates peristalsis in the lower oesophagus, stomach, intestine, the colon especially, and the bladder (Goodman and Gilman, 1955). But large doses cause spastic contracture (Sollmann, 1957), abdominal cramps being a recognized sign of neostigmine overdose. It is now apparent that the placenta acts as an ultra-filter: since complex substances like 7S $\gamma$-globulins cross the placenta from mother to foetus it is unlikely that neostigmine will not. So the massive maternal dose in this case

TABLE

Neonatal Deaths in Transient Neonatal Myasthenia Gravis

\begin{tabular}{|c|c|c|c|c|c|c|}
\hline Author & & $\begin{array}{l}\text { Age at } \\
\text { Death } \\
\text { (days) }\end{array}$ & $\begin{array}{l}\text { Maternal } \\
\text { Neostigmine } \\
\text { Daily Dose } \\
\quad(\mathbf{m g} .)\end{array}$ & Symptoms & $\begin{array}{l}\text { Treatment } \\
\text { (neonatal) }\end{array}$ & Necropsy Findings \\
\hline Strickroot et al. (1942) _. & $\cdots$ & 6 & 120 & $\begin{array}{l}\text { Feeding difficulty 3rd } \\
\text { day; loss of facial } \\
\text { tone }\end{array}$ & None & $\begin{array}{l}\text { Oedema and congestion } \\
\text { of brain; atelectasis; } \\
\text { mild hypertrophy of } \\
\text { thymus }\end{array}$ \\
\hline Wilson and Stoner (1944) & $\cdots$ & 4 & 135 & No cry; feeble sucking & None & $\begin{array}{l}\text { No congenital heart } \\
\text { disease or intracranial } \\
\text { haemorrhage }\end{array}$ \\
\hline $\begin{array}{l}\text { Kibrick }(1954) \quad \ldots \\
\text { Millichap and Dodge (1960) }\end{array}$ & $\ldots$ & 21 & $\begin{array}{c}90 \\
\text { Not given }\end{array}$ & $\begin{array}{c}\text { - } \\
\text { Not given }\end{array}$ & $\begin{array}{l}\text { Neostigmine } \\
\text { None }\end{array}$ & $\begin{array}{l}\text { Atelectasis and congestion } \\
\text { of lungs; slight hyper- } \\
\text { plasia of thymus } \\
\text { No details }\end{array}$ \\
\hline
\end{tabular}


would be an overdose to the foetus, causing prolonged spastic contracture of smooth muscle with subsequent work hypertrophy.

Generalized cardiac hypertrophy may be secondary to local or systemic disturbances. There was no evidence of cardiac failure, erythroblastosis, maternal diabetes, or abnormalities of the heart itself. The absence of placental inflammation and the paucity of cardiac glycogen exclude intrauterine infection (Potter, 1961), and glycogen storage disease as possible causes. No placental chorioangioma (Benson and Joseph, 1961) or cerebral arteriovenous aneurysm (Corrin, 1959) were discovered, and cardiac hypertrophy has not been described with hypoplastic lungs. The action of neostigmine on the heart is complex, and conclusions based on animal experiments are conflicting. Therapeutic doses cause peripheral vasodilatation, slowing and decreased heart action, and a fall in blood pressure. But some experiments have caused a rise in blood pressure mainly by a direct vasoconstrictive action on the intestinal vessels, partly by sensitization of the carotid sinus by a vasomotor reflex (Sollmann, 1957). Dale and Narayana (1935) observed that physostigmine caused vasoconstriction in the perfused pulmonary circulation. Hypertrophy of both ventricles is compatible with increased vascular resistance in both circulations, the right ventricle being more affected because of the shunt through the ductus arteriosus.

As smooth muscle hypertrophy has never been described in newborn infants of myasthenic mothers having neostigmine, particularly in high doses (Stone and Rider, 1949; Tether, 1955; Fraser and Turner, 1963), we accept that smooth muscle hypertrophy in an infant born to a myasthenic mother so treated may be a chance combination. But in view of the pharmacological actions of neostigmine we consider that a large maternal dose of neostigmine (800 mg. daily) crossing the placenta to the foetus could explain the findings in this case.

\section{Summary}

A newborn baby with smooth muscle hypertrophy of the oesophagus, stomach, pylorus, colon, and bladder born to a myasthenic mother is described. Polycystic kidneys, cardiac hypertrophy, and hypoplastic lungs were also present.

It is suggested that a large dose of neostigmine given throughout pregnancy could cause these muscle hypertrophies.

We wish to thank Dr. F. A. Langley for his advice and criticism and Professor W. I. C. Morris in whose department the work was done.

\section{REFERENCES}

Benson, P. F., and Joseph, M. C. (1961). Cardiomegaly in a newborn due to placental chorioangioma. Brit. med. F., 1, 102.

Corrin, B. (1959). Three cases of intracranial vascular malformations in infants. $\mathcal{F}$. clin. Path., 12, 412.

Dale, A. S., and Narayana, B. (1935). Observations on the perfused lungs of the guinea-pig. Quart. F. exp. Physiol., 25, 85.

Fraser, D., and Turner, J. W. A. (1963). Myasthenia gravis and pregnancy. Proc. roy. Soc. Med., 56, 379.

Goodman, L. S., and Gilman, A. Z. (1955). The Pharmacological Basis of Therapeutics, 2nd ed., p. 450. Macmillan, New York.

Guthrie, K. J. (1945). Idiopathic muscular hypertrophy of oesophagus, pylorus, duodenum and jejunum in a young girl. Arch. Dis. Childh., 20, 176.

Helmke, K. (1939). UUber Oesophagushypertrophie. Virchows Arch. path. Anat., 304, 79.

Kibrick, S. (1954). Myasthenia gravis in the newborn. Pediatrics, 14, 365 .

Millichap, J. G., and Dodge, P. R. (1960). Diagnosis and treatment of myasthenia gravis in infancy, childhood, and adolescence. Neurology (Minneap.), 10, 1007.

Potter, E. L. (1961). Pathology of the Fetus and Infant, 2nd ed., pp. 245, 445. Yearbook Medical Publishers, Chicago.

Pritchard, E., and Hillier, W. T. (1920). Specimens from a case of hypertrophic pyloric stenosis with associated hypertrophies. Proc. roy. Soc. Med., 13, Sect. Dis. Child., 33.

Rintoul, J. R., and Kirkman, N. F. (1961). The myenteric plexus in infantile hypertrophic pyloric stenosis. Arch. Dis. Childh., 36, 474.

Sloper, J. C. (1954). Idiopathic diffuse muscular hypertrophy of the lower oesophagus. Thorax, 9, 136.

Sollmann, T. (1957). A Manual of Pharmacology, 8th ed., p. 425. Saunders, Philadelphia.

Stone, C. T., and Rider, J. A. (1949). Treatment of myasthenia gravis. f. Amer. med. Ass., 141, 107.

Strickroot, F. L., Schaeffer, R. L., and Bergo, H. L. (1942). Myasthenia gravis occurring in an infant born of a myasthenic mother. ibid., 120, 1207.

Tether, J. E. (1955). Management of myasthenic and cholinergic crises. Amer. F. Med., 19, 740.

Wilson, A., and Stoner, H. B. (1944). Myasthenia gravis: a consideration of its causation in a study of fourteen cases. Quart. F. Med., 13, 1. 